\title{
Mesoeconomics of Development of the Oil and Gas Extraction Region
}

Pogodaeva Taisia V.

\author{
Rudenko Dmitry Y.
}

Simonova Ludmila M.

\section{Doi:10.5901/mjss.2014.v5n13p49}

Tyumen State University, Russia, Tyumen, 10 Semakova st. Email:drudenko@inbox.ru, Isim@utmn.ru , taisyapogodaeva@gmai.com

\begin{abstract}
The article describes the actual methodological issues of the economic mesosystem modernization based mainly on the region with the raw specialization and the oil and gas industries focus. The theoretical and statistical analysis of social and economic regional development during the last years is maintained. The unsolved problems in this area are identified, and anti crisis measures are suggested. The peculiarity of social-economical development of Tyumen region as the oil and gas exploration region and the directions of increasing the competitiveness of mesoeconomical system are determined. Suggested approaches can be applied for reforming the system of the regional governing, developing regional and social policies.
\end{abstract}

Keywords: Development, mesoeconomics, region, Russia.

\section{Introduction}

In the first decade of the twenty-first century, Russia reserves mainly raw specialization in the international division of labor. The country has a nonprogressive economic structure that painfully depends on the global situation with a clear dominance of its oil and gas sector as the main driver of economic development. The current situation is largely determined by the lack of systematic and coordinated interaction among the subjects of socio-economic development and strategic orientations of this development.

This problem is particularly acute for key oil and gas production regions that serve as primary abutment local formations and future growth drivers both for Russian economy at large and the neighboring communities. The Tyumen region, which is the focus of this research, is certainly among them.

The objective of the article is to determine strategic vectors, conditions and factors of the macro-economical regional system development, taking into consideration the following factors:

- peculiarity of the region which is the main oil and gas region of the country;

- peculiarity of the regional governing system;

- current regional policy of the Russian Federation.

In particular, the project is focused on:

- determining peculiarities of the current economical development and movement of the regions (a turn in the economic growth of Russia: archaism or development).

- evaluating the efficiency of the current regional policy and its implementation in the regions' development strategies (strategies of exploration versus strategies of development).

- identifying the main drivers and barriers for the strategic development of regional mesosystems (factors of "primary" and "secondary" nature).

\section{Methodology}

Recently both the idea of development relating to the Russian economy and the distinctness of the strategic benchmarks of this development are called into question in the scientific community. Declarativity of the mapped out modernization and innovative development strategy under the conditions of real economical recession, political policy preservation, mythologization of public conscience coupled with strengthening of propaganda efforts testify to the arkhaization of Russian public life, disclose counterintuitive transformation when "the old and the new switched places", as a result the guidepath also exchanged - instead of pressing forward "we go back". 
According to Kleyner (2011), the post-crisis period gives us a lesson which consists "in need of changing not so much the course as the "style" of Russian economic movement. Fundamental strategic mission is moving from oscillatory, zigzag, back and forth economy motion, which is typical of Russia, to another kind, with a development concept underneath".

It also fully refers to the regions, because mesoeconomic systems play the role of "specific conductors, moderators and amplifiers" of modernization initiatives for the Russian economy and the Russian society. Let us denote this strategic task as "mesoeconomy of development".

Let us prove that the current situation of political destabilization and economic stagnation is defined not so much by the lack of financial, material, intellectual and information resources (in all their significance) as by lack of both consistent and coordinated interaction of subjects of social and economic development, including regional level, and strategic benchmarks of this development.

Firstly, it is possible to diagnose the occurrence of the regional crisis in Russia, which is shown in economic, political, and the sociocultural relation. Indeed, the 2012-2013 monitoring showed that the regional economy is close to stagnation. Zero industrial production in 2013 and adverse external environment for the export sector played their negative part. According to Zubarevich (2014), in January-October 2013 the budgets income decreased in third of Russian regions, moreover the maximum recession was shown in the main oil and gas production region - the Tyumen region $(-28 \%)$. In almost $3 / 4$ regions the welfare expenses behavior was in arrears of budget expenses behavior in general. The regional budgets gap more than doubled and made 700 billion rubles during 2013. This deprives the regional authorities of the status of active and strong player in the economic area. As a result, the regions are not capable to solve social problems and problems of their own development by means of internal revenue sources mobilization. Thereby the main priority of regional policy in the economic domain - transition from budget payments to selfdevelopment of the regional economy - is called into question.

Economic powerlessness is accompanied by the loss of political influence and "weight" of regions, their opportunities and abilities to participate in the state and political administrative decision making. Figuratively speaking their influence area starts to "wind down" in the economic, sociocultural, political relations in the first place. The existing political system does not provide conditions and effective instruments for the accommodation of interests of different "center - regions" system levels.

The deficiency of new management mechanisms is compensated by imitating western samples, mechanical transferring them to the Russian ground in the form of "reforms" of various kinds which are not simply inorganic, but often destructive for the traditional vital environment of local communities. These multidimensional recessionary displays at the mesoeconomic level of the country allow to diagnose the oncoming of "axiological and cultural crisis", consisting in the inability and impossibility of regions to independently carry out the role of "designing their own future", to be engaged in their own development.

This, first of all, bears record to inefficiency of the existing regional policy, indicates that its priorities are not created and its tools work inefficiently. In spite of the fact that in the middle of 2000 in the "Strategy of development of Russia till 2020" there was a section on regional growth for the first time, the regional policy as a factor of development plays a limited role: in oil and gas extraction regions the implemented strategy is rather reclaiming than development.

\section{Results}

It is conventional to point out a dangerous trend of the increase in the gap between the center and districts, between macro-and micro-systems in Russia. Thus, regions differentiation by production per capita, indicating regional plant concentration, comes to $34 \%$ according to Gini index. In the Russian regional space $10 \%$ of Russian population make a third of gross domestic product of the country whereas other $10 \%$ in regions with the smallest productivity, limit their contribution to gross domestic product up to $3,5 \%$.

GRP per capita corrected according to the price level for Tyumen region with autonomous districts is 4 times greater than the Russian average, for Moscow - 1.8 times greater, only 17 regions have GRP per capita higher than the average. A quarter of all-country population lives in these regions. However, nearly $2 / 3$ of regions do not differ greatly according to the level of development - the difference is in the range between the average and its half. 2/3 of Russians live in them. GRP per capita less than $75 \%$ of the average can be observed in 45 Russian regions.

Differences between regions on economic conditions lead to significant differences in social conditions. The highest HDI score among Russia's regions has traditionally been recorded in Moscow, and the lowest score in Tyva Republic. Despite the fact that this indicator is a more comprehensive measure of well-being, the variation among the regions is driven to a large extent by differences in income per capita as differences with regard to life expectancy and 
education are small. Regional differentiation of the HDI has almost unchanged since 2002: "a little over 20\% of Russia's population live in relatively prosperous regions (including $8 \%$ in Moscow), about $10 \%$ in outsider regions, and more than two thirds live in regions with an average level of human development" (UNDP 2013, p.138).

Since regions are open systems, it is better to compare not GRP (as it is redistributed by the federal authorities), but income per capita. Analysis of this indicator in 2012 showed that the inequality among Russian regions is significantly less as maximum to minimum ratio equals to 4.7 (in 2007 - 8.9). Taking into account regional differences in price levels, the maximum exceeds the minimum at least about 3 times. Regional differentiation in incomes and per capita GRP decreased in 2002-2012 due to the Government's large-scale redistributive policies, and social inequality declined more sustainably.

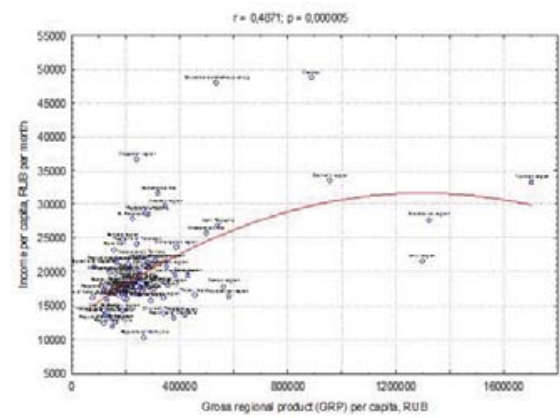

Figure 1. The interdependence of GRP per capita and money income per capita, 2012

Figure 1 shows a weak relationship between GRP and income per capita, with a higher level of production leads to a higher level of income, but in a declining power. This dependence explains why the regions are so different in terms of production, closer in terms of per capita income. This may be due to the fact that the calculation is based on the GRP and production data to a large extent depends on the location of the formal entities. The value added of resource extraction regions is distributed and used in other parts of the economy, mostly in the capital.

Dynamics of regional disparities in Russia can be considered using the Theil index, which allows us to decompose the rate of total inequality into two components reflecting interregional (caused by differences in average income between regions) and intra (observed within each region) economic inequality. Inequality within regions is more important fact in determining national levels of inequality than differences between regions.

Russian regions present the entire range of possible indicators of economic inequality, which is observed in the world, starting from the level of Latin American and ending level of some European countries. While income growth has also been accompanied by rising inequality and, except for Moscow, where the polarization of the population by income has declined. Rudenko (2011) proves the interdependence of economic growth and changes in income inequality in the Russian regions. The lowest differentiation is observed in depressed regions and consistent with its size in Croatia or Spain. The highest differentiation of income, comparable with the situation in Latin America, is observed in the leading regions with high level of life - in Moscow and the Tyumen region (Fig. 2).

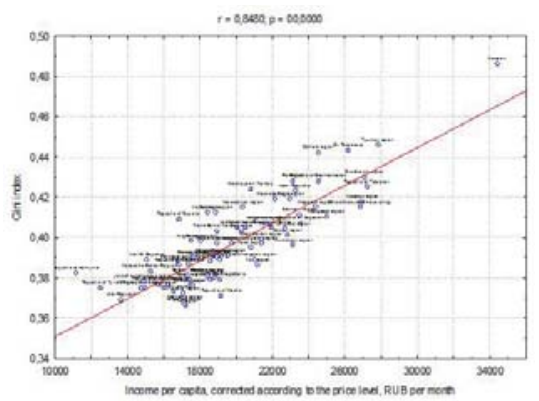

Figure 2. The interdependence of money income per capita and the level of inequality, 2012 
According to Zubarevich (2014) "the problem is not in disparity itself but in its negative influence on modernization of conditions and style of life. Large gap between several leaders and huge "median zone" slows down spatial spreading of innovations, since only one quarter of Russians live in places where resources for modernization are available". The oiland gas-rich area of the Sakhalin Region and Moscow together accounted for 25 per cent of all foreign direct investment (FDI) inflows in 2010-2012. Along with these two regions, Moscow, Tyumen, Vologda, Kaluga Leningrad, Omsk, Bryansk regions, St Petersburg (ten regions) accounted for 67 per cent of all FDI inflows over the same period. The concentration of the banking sector is also leading to disparate access to finance. According to Deutsche Bank (2009) "Moscow accounted for $31 \%$ of total loans and $50 \%$ of total deposits at the end of December 2008".

Therefore, the process of economic regionalization could be one of the major sources of social contradictions and conflicts in Russia, which is able to present a challenge to the sustainability of public administration in the next few years.

The Tyumen region, showing impressive dynamics of development, is more and more on the periphery, which means the part of the country that lives not for itself, but for serving the interests of the center. The presence of strong corporate players in the oil and gas regions leads to an actual substitution of the regional policy by corporate strategies in the regions of presence. The share growth of vertically integrated oil companies in the regional economy correlates with a decrease of their attributable return. Thus, the existing institutional system no longer provides the conditions and effective instruments for the accommodation of interests of different "center - regions" system levels. In relation to oil and gas extraction regions the option of a neocolonial policy of the center is realized.

The world experience says that a national economy can only be effective if it takes into account the peculiarities of the regions' development and relies on the following competitive advantages of those. Thereby the development and support of the regional mesoeconomic systems processes, as well as identifying the key factors and conditions of their development, especially applied to the traditional economics with a dominant raw specialization and the dominance of the oil and gas industries in their structure, acquire a special role.

On the one hand, the oil and gas sector itself is a problematic area of the economy because it is the source of the "resource curse" and the source of the extensive growth. On the other hand, a system modernization of the economy on the basis of innovations can only be possible and realizable if it is based on the oil and gas sector. This contradiction actualizes the problem of the meso-economic development unique model formation. On the one hand, it would have the essential characteristics of the innovation economy, giving an incentive to the development of the new and advanced technologies. On the other hand, it would ensure an effective integration of the oil and gas sector in this model and transformation of the sector into a high-tech and knowledge-intensive sphere, solving the problem of its susceptibility to the new technologies. And finally, it would take into account the basing area features of the modern oil and gas companies and the regional specific of the habitat and residence.

Special mention in this regard should be made of the specificity of settlement structure and the scheme of urbanization for the oil and gas extraction regions with intensive environmental management, particularly the problem of social and economic development of regions with high concentration of monotowns. Expert estimates confirm that in modern Russia monotowns are one of the key elements of the city network and make about $45 \%$ of total number of the cities. Thus, the problem of monotowns becomes nation-wide. The Ural federal district should be noted among the regions characterized by the prevalence of monoprofile settlements, containing critical mass of monotowns - about $62 \%$ of city structures of the region and, in particular, the Yamalo-Nenets Autonomous Area, where $55 \%$ of the population live in monotowns. Thus, the region comes to the first positions by the relevance of the non-diversity problem solving, imbalances of development, development of urgent measures and instruments of sustainable development of monotowns and their transfer to the innovative grounds.

Russia's WTO membership makes this problem actual due to the risks that should be first of all projected on monotown locations. According to the Ministry of Regional Development of the Russian Federation, there are 355 monotowns in Russia with the population about 16 million people that regard current diversification programs of development and economy modernization on the innovative grounds in order to prevent the major crisis phenomena.

Besides, the resolution of economic development contradictions of "North" and "South", social and economic binding of northern and southern territories, optimization of two keynotes - natural resources production on the one hand and an agribusiness industry on the other - is an acute problem for the Tyumen region.

These complex development problems cannot be solved without an essential change and reforming of the existing institutional system, change of the development ideology itself. The "demodernization mechanisms", certainly, prevail up till now. Among the factors determining the vector and conditions of the economical growth of the Tyumen region the dominating ones are of endogenous determinants, which are connected with natural conditions and natural resources of development. An institutional system negatively affects the development of the regional economic systems and it becomes the main barrier of their scientific and technical modernization. The factual development of the regions is mainly 
based on their own competitive advantages with a maximal consideration of the local peculiar endogenous factors of growth (factors of "primary nature" by Krugman P.). Whereas the institutional factors, which are of the "secondary nature", are highly politicized - they do not fulfill their stimulating function and do not provide an economical growth. At the same time, these factors influence and change the representation of the "primary nature" factors.

Realization of capital-intensive mega-projects on the territories of oil and gas exploitation should not be accompanied by simplification of its economics. On the contrary, it must lead to its complexity level growth along with improvement of the regional subjects' interaction, and to an increase of multiplication effects and a degree of localization on territories.

\section{Conclusion}

Fuel and energy industry should become a linking element of the whole system and a basic structure of scientific and technical modernization based on the resource advantages, with a reasonable balance of development priorities. The transformation of "governing colonization" practice should be supplemented with deregulation and decentralization with a simultaneous growth of the centre's role in development of a common scientific and technical policy in oil and gas regions.

Finally, the trajectory planning of the Tyumen region development as a leading oil and gas extraction province of Russia, claims multifaceted, triune approach to design the regional mesoeconomic system, providing the emerging interaction of three components: social (preservation of social and cultural subsystems' stability in the region), economic (enhancement of regional aggregate reserves usage) and ecological (preservation of ecological subsystems' ability to restore). Thus, regional growth is understood as "development without destruction". This logic is focused on the achievement of coherence between scientific and technological breakthrough, natural resources exploitation, the directions of investments, distributions of income and growth of quality of living of the population in the area, development balance of all components of region elements and subsystems.

\section{References}

Deutsche Bank (2009). Deutsche Bank Research. The Russian regions. < http://www.dbresearch.com/prod/dbr_internet_enprod/prod0000000000248042.pdf> (accessed may 30, 2014).

Farra, F., Klos, N., Schober, U., Sigalova, O. and Zhukov, A. (2013). Improving regional performance in Russia: a capability-based approach. < http://www.ebrd.com/downloads/research/economics/workingpapers/wp0155.pdf> (accessed May 30, 2014).

Kleyner, G.B. (2011). Mezoecomony of development: from crisis to anabasis. Economics. Taxes. Law, (5).

Krugman, F.R. (1993). Primary nature, secondary nature and metropolitan location. Journal of Regional Science, 33, 129-144.

Melnikova, L.V. (2013). Strategies of development or exploration: what is remained? ECO, 463 (2), 5-21.

Rosstat (2014). Social and Economic Indicators for Russia's Regions 2013. < http://www.gks.ru/bgd/regl/b13_14p/Main.htm> (accessed May 30, 2014).

Rudenko, D.Y. (2011). The poverty reduction strategy in a region. Tyumen: OLMARPRESS.

Trudolyubov, M. (2012). The old and the new change places. Vedomosti, 27 June

UNDP (2013). National Human Development Report for the Russian Federation 2013 / Edited by Prof. Sergey Bobylev/ Translation into English by Ben Hooson. Moscow: LLC RS Ilf.

Zubarevich, N.V. (2014). Regional development and regional policy in Russia. ECO, 478 (4), 6-27. 